Ann. Hum. Genet. (1997), 61, 121-136

\title{
A biometrical study of the relationship between sodium-lithium countertransport and triglycerides
}

\author{
J. H. STENGÅR ${ }^{1,2}$, K. E. ZERBA ${ }^{2}$, S. T. TURNER ${ }^{3}$ ANd C. F. SING ${ }^{2}$ \\ ${ }^{1}$ National Public Health Institute, Department of Epidemiology and Health Promotion, \\ Helsinki, Finland \\ ${ }^{2}$ Department of Human Genetics, University of Michigan Medical School, Ann Arbor, MI, U.S.A. \\ ${ }^{3}$ Division of Hypertension, Department of Internal Medicine, Mayo Clinic Foundation, \\ Rochester, MN, U.S.A.
}

(Received 27.8.96. Accepted 13.12.96)

\section{SUMMARY}

We addressed the question: Is there evidence that allelic variation in a single unmeasured gene that has a large effect on maximal activity of erythrocyte sodium-lithium countertransport (Na-Li CNT) also has pleiotropic effects on variation in plasma triglyceride levels? Complex segregation analysis models that included plasma triglyceride levels as a covariate were considered as explanations for interindividual variation in Na-Li CNT. A sample of 711 healthy adults from 254 pedigrees enrolled in the Rochester Family Heart Study was selected for this study. The majority of the pedigrees supported the hypothesis that variations in a single unmeasured non-transmitted environmental factor have large effects on the Na-Li CNT distribution. Only gender-specific first-order covariate parameters were necessary in the complex segregation models suggesting that the form of the relationship between Na-Li CNT and plasma triglyceride level was not influenced by variation in the inferred environmental factor with large effects. Stratification of the sample by this inferred environmental factor resulted in three classes of individuals with significant differences in the distributions of coronary heart disease risk factor traits, as well as interindividual variation in both Na-Li CNT and plasma triglyceride levels. These results, along with other observations from the Rochester Family Heart Study sample, emphasize the complex and multifactorial nature of the causes of interindividual variation in Na-Li CNT. Our study further suggests that new research strategies are needed for studying the relationships between genetic and environmental variation and variation in quantitative traits such as Na-Li CNT that have been identified as risk factors for hypertension.

\section{INTRODUCTION}

Blood pressure levels aggregate in families (Miall \& Oldham 1963) and genetic variation may be responsible for a fraction of its interindividual differences in the population at large (Pickering 1967). About $30 \%$ of interindividual

Correspondence: Charles F. Sing, Department of Human Genetics, 4708 Medical Science Bldg. II, University of Michigan Medical School, Ann Arbor, MI 48109-0618, U.S.A. Tel (313) 764-5492, Fax (313) 763-5277. E.mail : csing@umich.edu variation in office blood pressure levels has been attributed to variation in genetic factors and the remainder to variation in exposures to environmental factors (Annest et al. 1979; Sing \& Boerwinkle 1985; Sing et al. 1986; Ward 1990). Efforts are underway to estimate the fraction of variation in blood pressure associated with measures of common allelic variation in genes known to be involved in blood pressure regulation (Jeunemaitre et al. 1992; Hixson \& Powers 1994). However, this candidate gene approach to revealing the genetic architecture (Sing et al. 
1986) of interindividual variation in blood pressure cannot reveal the contribution of genes that are unknown. In contrast, a biometrical unmeasured genotype approach evaluates the distribution of phenotypic variations among family members to identify individuals most likely to carry alleles at unknown genes responsible for genetic variation in the trait of interest (Sing et al. 1988).

One strategy that employs the biometric approach to evaluate the impact of unknown genetic factors on blood pressure is to analyse interindividual variation in intermediate physiological or biochemical traits responsible for linking genetic variation to variation in blood pressure (Sing et al. 1986; Rebbeck et al. 1991). Erythrocyte sodium-lithium countertransport may serve as such an intermediate biochemical trait (Canessa et al. 1980; Boerwinkle et al. 1986; Rebbeck et al. 1991; Rutherford et al. 1992a). The maximal rate of sodium-lithium countertransport (Na-Li CNT) is elevated in hypertensive patients and in their normotensive firstdegree relatives compared to unrelated normotensive controls (Canessa et al. 1980). A hypothesized association between Na-Li CNT in erythrocytes and sodium-hydrogen exchange activity in vascular smooth muscle or renal tubular cells may be the biological basis for a link between variation in Na-Li CNT and interindividual variation in blood pressure (Rutherford et al. 1992a).

Multimodality in the Na-Li CNT distribution in the population at large (Boerwinkle et al. 1986; Turner \& Michels 1991) suggests the possibility of large effects of allelic variations in a single gene. Biometrical genetic studies of NaLi CNT, however, have produced multiple explanations for this multimodality (Boerwinkle et al. 1986; Dadone et al. 1984; Hasstedt et al. 1988). A biometrical top-down study of individuals unselected for health status found subgroups of pedigrees in the same population that gave support for either a single genetic factor with large allelic effects or a single non-transmitted environmental factor with large effects (Rebbeck et al. 1991). The majority (65-85\%) of the total phenotypic variability in Na-Li CNT could not be explained by variation in either a single genetic or a single environmental factor (Rebbeck et al. 1991). Other unmeasured factors undoubtedly play the greatest role in determining interindividual variation in Na-Li CNT.

Measured genotype studies suggest that genetic variation may have pleiotropic effects on the means, variances, covariances, and regression relationships among several of the intermediate biochemical and physiological traits that link genetic variation with variation in risk of disease (Boerwinkle et al. 1987; Reilly et al. 1991, 1992, 1994). In this paper we consider the hypothesis that covariation between Na-Li CNT and plasma triglyceride levels may be a consequence of pleiotropic effects of a single, unmeasured, gene that has been shown to have major effects on interindividual variation in Na-Li CNT. This possibility was tested by applying the methods of complex segregation analysis to models for variation in Na-Li CNT that considered plasma triglyceride level as a covariate. Plasma triglyceride was selected as a covariate because epidemiological studies suggest that variation in plasma triglyceride levels is a statistically significant predictor of interindividual variation in Na-Li CNT (Hunt et al. 1986; Turner et al. 1989). We considered separate models of the relationship between Na-Li CNT and plasma triglyceride levels for females and males because there is evidence that the distribution of $\mathrm{Na}-\mathrm{Li}$ CNT is gender specific (Turner et al. 1989; Rebbeck et al. 1991).

A sample of 711 adults from 254 pedigrees enrolled in the Rochester Family Heart Study (RFHS) (Moll et al. 1989) was selected for this study. A majority of the pedigrees supported the presence of variation in a single unmeasured nontransmitted environmental factor with major effects on the distribution of Na-Li CNT when a gender-specific linear relationship with plasma triglyceride levels was included in the models for complex segregation analyses. Gender-specific slopes were not significantly influenced by variation in this unknown non-transmitted environmental factor. Stratification of the sample by 
this inferred environmental factor resulted in three classes of individuals with significant heterogeneity in the distributions of coronary heart disease risk factor traits, including intraclass variation in both Na-Li CNT and plasma triglyceride levels. These observations document the co-dependence of the phenotypes of numerous metabolic traits that are frequently involved in identifying individuals at risk of disease (Ferrannini 1991).

\section{MATERIALS AND METHODS}

\section{Sample}

Pedigrees for the RFHS were ascertained through households with two or more children in the Rochester, MN, school system in January 1984 (Moll et al. 1989; Turner et al. 1989). Altogether 2004 individuals from 283 pedigrees visited the Mayo Clinic between 1984 and 1987 for blood drawing and clinical examination. We excluded individuals younger than 20 years of age from the current sample because they shared $\mathrm{Na}$ Li CNT assay date with their siblings more often than older subjects, resulting in the possibility that the effects due to shared genes and shared environments may be confounded (Rebbeck et al. 1991). Of the adults, 24 non-fasting and 14 randomly-selected individuals from 14 twin pairs were excluded prior to analysis. Only one individual was selected to represent each of the twin pairs because zygosity of the pairs was not known. Furthermore, we excluded 351 individuals taking drugs that may influence plasma lipid levels, including diuretics, alpha- and betablockers, glucocorticoids, insulin, oral antidiabetics, thyroid drugs, estrogen and progesterone. We also excluded 184 current smokers and 9 diet-treated diabetics because both smoking and diabetes are known to influence plasma lipid levels. The resulting sample included 711 individuals age 20 to 90 years distributed in 254 pedigrees. The average number of individuals per pedigree was $2 \cdot 80$. Although the average pedigree size was relatively small, the number of pedigrees, where three or more individuals repre- sented a pedigree was 115 , of which 32 consisted of five or more individuals.

\section{Study protocol}

All activities involving human subjects were reviewed and approved by the Institutional Review Board of the Mayo Clinic and were carried out in accordance with guidelines at the institution. This study involved minimal risk so only verbal consent was required. All subjects visited the Mayo Clinic between 7:00 and 9:00 a.m., and had been requested to fast overnight and complete a questionnaire regarding use of prescription and non-prescription medications. A blood sample was drawn from an antecubital vein for laboratory analysis. A brief physical examination was performed. Body weight was measured on a beam balance in light clothing, and height was determined with a wall stadiometer. Blood pressure was measured with a random-zero sphygmomanometer (Hawksley \& Sons, Ltd, West Sussex, England) after selection of a cuff size appropriate for subject's arm. Pressure at the Korotkoff phase I sound was taken as systolic blood pressure, and pressure at the Korotkoff phase $\mathrm{V}$ sound was taken as diastolic blood pressure. The averages of three systolic and three diastolic blood pressure readings at least $2 \mathrm{~min}$ apart were used as the blood pressure values in this study.

\section{Laboratory measurements}

Blood samples were anticoagulated with heparin and kept at $4{ }^{\circ} \mathrm{C}$ until processing for laboratory assays. Methods developed by Canessa and Tosteson were used to estimate NaLi CNT as the rate of lithium efflux from lithium loaded erythrocytes (Canessa \& Tosteson 1979). Further details of the procedures to determine Na-Li CNT, including data to support the conclusion that a single assay provides a reliable measure of an individual's Na-Li CNT, are given elsewhere (Turner et al. 1989; Turner \& Michels 1991). Plasma total cholesterol and triglyceride levels were measured using standard enzymatic methods (Kottke et al. 1991) with quality control plasma pools. Similarly, high density lipoprotein 
(HDL) cholesterol was measured by enzymatic method after precipitation of low density lipoprotein and very low density lipoprotein particles by polyethylene glycol 6000. This method gives values that are the same as those obtained with Lipid Research Clinic heparin-manganese method and avoids cloudy supernatant and the potential for inference with the enzymatic determination of cholesterol (Kottke et al. 1991).

\section{Statistical analysis}

Complex segregation analysis (Elston \& Stewart 1971; Lalouel et al. 1983) was used to estimate parameters and to test hypotheses about the causes of interindividual variation in Na-Li CNT represented by these parameters. Hypotheses were tested by comparing a series of models that describe the distribution of $\mathrm{Na}-\mathrm{Li}$ CNT among members of pedigrees. Each model included a different combination of parameters that define a different combination of genderspecific genetic and environmental factors, and a measured covariate, plasma triglyceride levels. A general transmission model (GT), or unified model (Lalouel et al. 1983), was the most complete model considered. Under this model, interindividual variation of Na-Li CNT is explained by independent and additive contributions of (1) variation in a single factor having major effects on Na-Li CNT and/or the relationship between Na-Li CNT and plasma triglyceride levels, (2) small additive allelic contributions of a large number of independent polygenes that are associated with deviations of Na-Li CN'T not associated with the single factor, and (3) contributions of variation in individualspecific environments associated with the remainder of interindividual variation. The single major factor was modeled as having two alternatives, C (a common alternative having a small effect) and $\mathrm{R}$ (a rare alternative having a large effect), that may have either a genetic or environmental origin. These alternatives combine to determine three classes, ousiotypes (Cannings et al. 1978), of individuals denoted CC, $\mathrm{CR}$ and $\mathrm{RR}$ in this paper. Regardless of whether $\mathrm{C}$ and $\mathrm{R}$ are genetic or environmental factors, their relative frequencies in the population being sampled are taken to be $p$ and $1-p$, respectively. Assuming random association of $\mathrm{C}$ and $\mathrm{R}$, the relative proportions of $\mathrm{CC}, \mathrm{CR}$ and $\mathrm{RR}$ in population at large are taken to be $p^{2}, 2 p(1-p)$ and $(1-p)^{2}$, respectively. The gender-specific distribution of Na-Li CNT within each ousiotype is assumed to be normal, with ousiotype-specific mean, $\alpha_{\mathrm{og}}+\beta_{\mathrm{og}}^{\mathrm{L}} *($ trig $)+\beta_{\mathrm{og}}^{\mathrm{Q}} *(\text { trig })^{2}$, and common phenotypic variance $\left(\sigma_{\text {ue }}^{2}\right)$, where o refers to ousiotype CC, CR or RR, and g represents gender ( $\mathrm{F}$ for females and $\mathrm{M}$ for males). The GT model included six $\alpha_{\mathrm{og}}$ parameters to represent the six gender- and ousiotype-specific intercepts, six $\beta_{\mathrm{og}}^{\mathrm{L}}$ and six $\beta_{\mathrm{og}}^{\mathrm{Q}}$ parameters associated with the first and the second order polynomial relationship, respectively, for the plasma triglyceride dependent distribution of Na-Li CNT within the six gender- and ousiotype-specific strata. We considered separate models of the relationship between Na-Li CNT and plasma triglyceride levels for females and males because there is evidence that the distribution of Na-Li CNT is gender specific (Turner et al. 1989; Rebbeck et al. $1991)$. The common variance $\left(\sigma_{\text {ue }}^{2}\right)$ of deviations of Na-Li CN'T about each ousiotype mean defined by the polynomial equation was partitioned into two components (1) the additive effects of polygenes $\left(\sigma_{\mathrm{pg}}^{2}\right)$ and $(2)$ individual specific environmental effects and measurement errors $\left(\sigma_{\mathrm{e}}^{2}\right)$. The other parameters of the GT model include transmission parameters $\tau_{1}, \tau_{2}$ and $\tau_{3}$, which represent the probabilities that an individual with ousiotype $\mathrm{CC}, \mathrm{CR}$ or $\mathrm{RR}$, respectively, transmits the alternative $\mathrm{C}$ to his or her offspring. In general, $\tau\left(\mathrm{O}_{\mathrm{o}} \mid \mathrm{O}_{\mathrm{m}}, \mathrm{O}_{\mathrm{f}}\right)$ is the probability that an offspring has the ousiotype $\mathrm{O}_{\mathrm{o}}$, given the $\mathrm{O}_{\mathrm{m}}$ and $\mathrm{O}_{\mathrm{f}}$ ousiotypes of the mother and father, respectively. Each of the $\tau_{1}, \tau_{2}$ and $\tau_{3}$ under the GT model were estimated under the constraint that they be within the interval 0 to 1 .

In the models that included genetic components (a single major gene and/or polygenes), we assumed Hardy-Weinberg equilibrium at all loci, no epistasis, no linkage disequilibrium between pairs of loci and no genotype by environment interaction. Furthermore, in cases 
where polygenes were included in the model, deviations attributable to dominance were assumed absent.

Six alternative models to the GT model were considered. Each represents a restriction of one or more of the parameters of the GT model. The values of the transmission parameters were altered to reflect either the major effects of a single environmental factor or a single genetic factor. For environmental models representing either the mixed action of an unknown nontransmitted environmental factor and polygenes $(\mathrm{ME}+\mathrm{PG})$ or the action of an unknown nontransmitted environmental factor alone (ME only), the transmission parameters were restricted to be equal to the relative frequency of C, i.e. $\tau_{1}=\tau_{2}=\tau_{3}=p$. Hence, for these models the probability of observing an offsprings' ousiotype is independent of the parental ousiotypes and hence the unknown factor associated with phenotypic differences is not transmitted from one generation to another. Genetic models of either the mixed action of a single major gene with polygenes $(\mathrm{MG}+\mathrm{PG})$ or action of a single major gene alone (MG only) restricted the transmission probabilities to the values expected under Mendelian transmission, i.e. $\tau_{1}=1, \tau_{2}=0.5$ and $\tau_{3}=0$. Models that considered only either a single major non-transmitted environmental factor (ME only) or a single major gene (MG only) restricted the additive genetic variance $\sigma_{\mathrm{pg}}^{2}$ to be zero. A polygenic model ( $\mathrm{PG}$ only) explains the plasma triglyceride dependent distribution of Na-Li CNT without the single major factor. Hence the transmission probabilities and separate ousiotype means were not included in this model. Finally, the sporadic model (S) describes the phenotypic variation of Na-Li CNT by a triglyceride dependent mean and deviations about this mean associated with variation in individual-specific environmental factors and measurement errors. The parameters of the sporadic model were the same as those considered in a polynomial regression analysis that ignores the six gender- and ousiotype-specific strata.

Parameter estimates were those that maximized the likelihood of a model, given the observed data. The likelihoods were computed by using the pedigree analysis package (PAP) developed by Hasstedt (Hasstedt \& Cartwright 1981). This package employs an approximation of the likelihood for the mixed models $\left(\sigma_{\mathrm{pg}}^{2} \neq 0\right)$ and exact likelihood for all other models. The likelihood for each model considered was maximized by using a quasi-Newton optimization method implemented in the GEMINI computer program (Lalouel 1979).

Hypothesis testing was accomplished in two steps. First we restricted one or more parameter values defined by a null hypothesis and estimated the remaining parameters from the data. Second we compared the maximum likelihood of that model with the maximum of the likelihood of the GT model with all parameters estimated. Asymptotically, minus twice the difference between the maximum of the $\log _{\mathrm{e}}$ likelihoods of these two models is distributed approximately as $\chi^{2}$, when the null hypothesis is true. The D.F. for this $\chi^{2}$ statistic are equal to the number of independent parameters restricted by the particular null hypothesis. The level of statistical significance was taken to be $\alpha=0.05$ unless otherwise designated.

RESULTS

\section{Sample characteristics}

The sample included 367 females and 344 males. Mean age for females was $49 \cdot 4 \mathrm{yr}$ (s.D. $=$ $16 \cdot 0$, range $20 \cdot 3-90 \cdot 3 \mathrm{yr}$ ) and for males was $47 \cdot 8$ yr (s.D. $=16 \cdot 2$, range $20 \cdot 0-89 \cdot 4 \mathrm{yr}$ ). Mean Na-Li CNT of females was $268.0 \mu \mathrm{mol} \mathrm{l}{ }^{-1} \mathrm{RBCh}^{-1}$ (s.D. $=91 \cdot 9$, range $73 \cdot 2$ to $733.9 \mu \mathrm{mol} \mathrm{l}^{-1} \mathrm{RBC}$ $\mathrm{h}^{-1}$ ) and mean plasma triglyceride level was $112 \cdot 2 \mathrm{mg} \mathrm{dl}^{-1}$ (S.D. $=59 \cdot 0$, range $38 \cdot 0-452 \cdot 0 \mathrm{mg}$ $\mathrm{dl}^{-1}$ ). In males the respective values were $313.6 \mu \mathrm{mol} \mathrm{l}^{-1}$ RBC $\mathrm{h}^{-1} \quad$ (s.D. $=106 \cdot 7$, range $70 \cdot 5-675 \cdot 1 \mu \mathrm{mol} \mathrm{l}^{-1} \mathrm{RBC} \mathrm{h}^{-1}$ ) and $136 \cdot 4 \mathrm{mg} \mathrm{dl}^{-1}$ (s.D. $=75 \cdot 3$, range $33 \cdot 0-520 \cdot 0 \mathrm{mg} \mathrm{dl}^{-1}$ ). The best fitting polynomial regression of Na-Li CNT on plasma triglyceride was $\mathrm{CNT}=215 \cdot 709+0 \cdot 465 \times$ TRIG in females $\left(R^{2} \times 100=8 \cdot 6, p<0 \cdot 001\right)$ and $\mathrm{CNT}=220 \cdot 096+0.871 \times \mathrm{TRIG}+0 \cdot 001 \times \mathrm{TRIG}^{2}$ in males $\left(R^{2} \times 100=10 \cdot 6, p<0 \cdot 001\right)$. 


\section{Complex segregation analyses}

Our first step was to determine the nature of the gender-specific association between $\mathrm{Na}-\mathrm{Li}$ CNT and plasma triglyceride levels defined by the GT model. To test the null hypothesis that an ousiotype-specific second order polynomial was not necessary, we constrained the second order terms to zero (i.e. $\beta_{\mathrm{CCF}}^{\mathrm{Q}}=\beta_{\mathrm{CRF}}^{\mathrm{Q}}=\beta_{\mathrm{RRF}}^{\mathrm{Q}}=\beta_{\mathrm{CCM}}^{\mathrm{Q}}=$ $\left.\beta_{\mathrm{CRM}}^{\mathrm{Q}}=\beta_{\mathrm{RRM}}^{\mathrm{Q}}=0\right)$. This restricted model could not be rejected $\left(\chi^{2}=0.423\right.$, D.F. $\left.=6, p>0.05\right)$ compared to the most complete GT model $\left(\mathrm{GT}_{24}\right.$ in Table 1, first column). We next considered a model which constrained both first and second order terms to be zero (i.e. $\beta_{\mathrm{CCF}}^{\mathrm{L}}=\beta_{\mathrm{CRF}}^{\mathrm{L}}=\beta_{\mathrm{RRF}}^{\mathrm{L}}=$ $\beta^{\mathrm{L}}{ }_{\mathrm{CCM}}=\beta_{\mathrm{CRM}}^{\mathrm{L}}=\beta_{\mathrm{RRM}}^{\mathrm{L}}=0$ and $\beta_{\mathrm{CCF}}^{\mathrm{Q}}=\beta_{\mathrm{CRF}}^{\mathrm{Q}}=$ $\beta_{\mathrm{RRF}}^{\mathrm{Q}}=\beta_{\mathrm{CCM}}^{\mathrm{Q}}=\beta_{\mathrm{CRM}}^{\mathrm{Q}}=\beta_{\mathrm{RRM}}^{\mathrm{Q}}=0$ ). This reduced model of no relationship between Na-Li CNT and plasma triglyceride levels was rejected with $\chi^{2}=$ $98 \cdot 132$ (D.F. $=12, p<0.001$ ) compared to the $\mathrm{GT}_{24}$ model. This result provides strong evidence that a linear relationship between Na-Li CNT and plasma triglyceride levels should be included in the complex segregation analyses of $\mathrm{Na}-\mathrm{Li}$ CNT.

Next we tested a hypothesis of homogeneity of gender-specific first order terms among ousiotypes (i.e. $\beta_{\mathrm{CCF}}=\beta_{\mathrm{CRF}}=\beta_{\mathrm{RRF}} \neq 0$ and $\beta_{\mathrm{CCM}}=$ $\left.\beta_{\mathrm{CRM}}=\beta_{\mathrm{RRM}} \neq 0\right)$. This restricted model could not be rejected compared to the $\mathrm{GT}_{24}$ model $\left(\chi^{2}=9 \cdot 772\right.$, D.F. $\left.=10, p>0 \cdot 05\right)$. Failure to reject this 'reduced' GT model $\left(\mathrm{GT}_{14}\right.$ in Table 1 , second column), suggests that the linear relationship between Na-Li CNT and plasma triglyceride levels is not heterogeneous across gender-specific ousiotypes. Hence, this 'reduced' model was considered as our GT model for contrasting subsequent reduced models that test hypotheses about the causes of genetic and environmental sources of interindividual variation in $\mathrm{Na}-\mathrm{Li}$ CNT.

Each of the six reduced models, in which one or more genetic parameters $\tau_{1}, \tau_{2}, \tau_{3}, p$ and $\sigma_{\mathrm{pg}}^{2}$ were restricted to values defined by a null hypothesis, was rejected compared to the $\mathrm{GT}_{14}$ model. Comparisons between the $\mathrm{GT}_{14}$ model and the polygenic or sporadic models are not straight- forward because of the theoretical problem in defining the appropriate degrees of freedom for the $\chi^{2}$-distribution when contrasting a unimodal distribution (the polygenic and sporadic models) with a multimodal distribution (the $\mathrm{GT}_{14}$ model) (Titterington et al. 1985). However, in this study both the polygenic and sporadic models were so clearly rejected $\left(\chi^{2}=131 \cdot 100\right.$ with D.F. $=18$ and $\chi^{2}=166.004$ with D.F. $=19$, respectively) compared to the $\mathrm{GT}_{14}$ model that expected biases in the definition of the D.F. cannot influence our conclusions. The maximum likelihood estimates (MLEs) of the parameters that define the $\mathrm{GT}_{24}$ and the $\mathrm{GT}_{14}$ models and each of the six reduced models are presented in Table 1 .

Rejection of the polygenic and sporadic models (Table 1) when compared to the $\mathrm{GT}_{14}$ model provides strong evidence for the presence of variation in a single factor with large effects on Na-Li CNT level. Unfortunately, no general inference can be made about the nature of this single factor since both the major gene hypothesis (models 'MG+PG' and 'MG only' columns 4 and 6 in Table 1 ) and the hypothesis of a major non-transmitted environmental factor (models 'ME + PG' and 'ME only' columns 3 and 5 in Table 1) were rejected compared to the $\mathrm{GT}_{14}$ model. There are at least two possible explanations for this finding. First, there may be a third, yet undefined, model which explains the Na-Li CNT distribution better than any of the models we used, including the $\mathrm{GT}_{24}$ model. We did not explore this possibility. Second, there may be heterogeneity among pedigrees in the factor causing the large effect on interindividual variation in Na-Li CNT. In this case our sample may represent a mixture of pedigrees, some of which are consistent with the segregation of a single gene with large effect on the intercept of the linear relationship between Na-Li CNT and plasma triglyceride levels and others which are consistent with similar phenotypic effects of variation in a single non-transmitted environmental factor.

We next assessed evidence for heterogeneity of the causation of the large effects among pedigrees by considering the relative support of each 
Table 1. Maximum likelihood parameter estimates and $\chi^{2}$ statistics when applying complex segregation models that considered plasma triglyceride levels $\left(\mathrm{mg} \mathrm{dl}^{-1}\right)$ as a covariate for interindividual variation in Na-Li CNT ( mol l l $^{-1}$ RBC $\left.h^{-1}\right)$

\begin{tabular}{|c|c|c|c|c|c|c|c|c|}
\hline Parameter & $\mathrm{GT}^{\mathrm{a}}{ }_{24}$ & $\mathrm{GT}^{\mathrm{b}}{ }_{14}$ & $\mathrm{ME}+\mathrm{PG}^{\mathrm{b}}$ & $\mathrm{MG}+\mathrm{PG}^{\mathrm{b}}$ & ME only ${ }^{b}$ & MG only ${ }^{\mathrm{b}}$ & PG only ${ }^{\mathrm{c}}$ & $\mathrm{S}^{\mathrm{c}}$ \\
\hline$p$ & $0 \cdot 853$ & $0 \cdot 856$ & $0 \cdot 837$ & $0 \cdot 832$ & $0 \cdot 838$ & $0 \cdot 828$ & $(1 \cdot 0)$ & $(1 \cdot 0)$ \\
\hline$\alpha_{\mathrm{CCF}}$ & $178 \cdot 4$ & $182 \cdot 764$ & $185 \cdot 772$ & $187 \cdot 387$ & $181 \cdot 503$ & $184 \cdot 953$ & $220 \cdot 899$ & $215 \cdot 692$ \\
\hline$\alpha_{\mathrm{CRF}}$ & $241 \cdot 423$ & $291 \cdot 090$ & $291 \cdot 453$ & $283 \cdot 482$ & $293 \cdot 593$ & $288 \cdot 418$ & $220 \cdot 899$ & $215 \cdot 692$ \\
\hline$\alpha_{\mathrm{RRF}}$ & $448 \cdot 358$ & $555 \cdot 440$ & $552 \cdot 882$ & $573 \cdot 166$ & $558 \cdot 764$ & $560 \cdot 744$ & $220 \cdot 899$ & $215 \cdot 692$ \\
\hline$\beta^{\mathrm{L}}{ }_{\mathrm{CCF}}$ & $0 \cdot 558$ & $0 \cdot 440$ & $0 \cdot 426$ & $0 \cdot 422$ & 0.425 & $0 \cdot 405$ & $0 \cdot 436$ & $0 \cdot 466$ \\
\hline$\beta^{\mathrm{L}}{ }_{\mathrm{CRF}}$ & $1 \cdot 020$ & $0 \cdot 440$ & $0 \cdot 426$ & $0 \cdot 422$ & $0 \cdot 425$ & $0 \cdot 405$ & $0 \cdot 436$ & $0 \cdot 466$ \\
\hline$\beta_{\mathrm{RRF}}^{\mathrm{L}}$ & $1 \cdot 941$ & $0 \cdot 440$ & $0 \cdot 426$ & $0 \cdot 422$ & $0 \cdot 425$ & $0 \cdot 405$ & $0 \cdot 436$ & $0 \cdot 466$ \\
\hline$\beta_{\mathrm{CCF}}^{\mathrm{Q}}$ & $-0 \cdot 0006$ & 0 & 0 & 0 & 0 & 0 & 0 & 0 \\
\hline$\beta_{\mathrm{CRF}}^{Q}$ & $-0 \cdot 0011$ & 0 & 0 & 0 & 0 & 0 & 0 & 0 \\
\hline$\beta_{\mathrm{RRF}}^{\mathrm{Q}}$ & $-0 \cdot 0033$ & 0 & 0 & 0 & 0 & 0 & 0 & 0 \\
\hline$\alpha_{\mathrm{CCM}}$ & $202 \cdot 164$ & $211 \cdot 719$ & $213 \cdot 110$ & $212 \cdot 567$ & $216 \cdot 646$ & $213 \cdot 319$ & $252 \cdot 697$ & $253 \cdot 669$ \\
\hline$\alpha_{\mathrm{CRM}}$ & $264 \cdot 583$ & $364 \cdot 768$ & $363 \cdot 300$ & $364 \cdot 817$ & $377 \cdot 584$ & $364 \cdot 935$ & $252 \cdot 697$ & $253 \cdot 669$ \\
\hline$\alpha_{\mathrm{RRM}}$ & $684 \cdot 387$ & $534 \cdot 112$ & 533.989 & $544 \cdot 906$ & $537 \cdot 376$ & $522 \cdot 974$ & $252 \cdot 697$ & $253 \cdot 669$ \\
\hline$\beta_{\mathrm{CCM}}^{\mathrm{L}}$ & $0 \cdot 416$ & $0 \cdot 341$ & $0 \cdot 340$ & $0 \cdot 349$ & $0 \cdot 324$ & $0 \cdot 344$ & $0 \cdot 438$ & $0 \cdot 439$ \\
\hline$\beta_{\mathrm{CRM}}^{\mathrm{L}}$ & $1 \cdot 601$ & $0 \cdot 341$ & $0 \cdot 340$ & $0 \cdot 349$ & $0 \cdot 324$ & $0 \cdot 344$ & $0 \cdot 438$ & $0 \cdot 439$ \\
\hline$\beta_{\text {RRM }}^{\mathrm{L}}$ & $-1 \cdot 543$ & $0 \cdot 341$ & $0 \cdot 340$ & $0 \cdot 349$ & $0 \cdot 324$ & $0 \cdot 344$ & $0 \cdot 438$ & $0 \cdot 439$ \\
\hline$\beta_{\mathrm{CCM}}^{\mathrm{Q}}$ & $0 \cdot 000005$ & 0 & 0 & 0 & 0 & 0 & 0 & 0 \\
\hline$\beta_{\mathrm{CRM}}^{\mathrm{Q}}$ & $-0 \cdot 0035$ & 0 & 0 & 0 & 0 & 0 & 0 & 0 \\
\hline$\beta_{\mathrm{RRM}}^{\mathrm{Q}}$ & $0 \cdot 0040$ & 0 & 0 & 0 & 0 & 0 & 0 & 0 \\
\hline$\sigma_{p g}^{2}$ & $2602 \cdot 344$ & $2658 \cdot 061$ & $2871 \cdot 434$ & $1927 \cdot 808$ & 0 & 0 & $6028 \cdot 801$ & 0 \\
\hline$\sigma^{2}{ }^{p g}$ & $536 \cdot 793$ & $450 \cdot 782$ & $315 \cdot 507$ & $1648 \cdot 830$ & $3077 \cdot 143$ & $3406 \cdot 707$ & $2916 \cdot 008$ & $8932 \cdot 329$ \\
\hline$\tau_{1}$ & $0 \cdot 886$ & $0 \cdot 892$ & (p) & $(1 \cdot 0)$ & $(p)$ & $(1 \cdot 0)$ & - & - \\
\hline$\tau_{2}$ & $0 \cdot 560$ & $0 \cdot 593$ & (p) & $(0 \cdot 5)$ & (p) & $(0 \cdot 5)$ & - & - \\
\hline$\tau_{3}$ & $0 \cdot 586$ & $0 \cdot 453$ & (p) & $(0 \cdot 0)$ & (p) & $(0 \cdot 0)$ & - & - \\
\hline$-\log _{\mathrm{e}} \mathrm{L}$ & $4155 \cdot 164$ & $4160 \cdot 050$ & $4164 \cdot 888$ & $4172 \cdot 489$ & $4182 \cdot 178$ & $4177 \cdot 913$ & $4225 \cdot 600$ & $4243 \cdot 052$ \\
\hline$x^{2}$ & & $9 \cdot 772(\mathrm{NS})$ & & & & & & \\
\hline D.F. & & 10 & & & & & & \\
\hline$\chi^{2}$ & & & $9 \cdot 676^{*}$ & $24 \cdot 878 * *$ & $44 \cdot 256 * * *$ & $35 \cdot 726 * * *$ & $131 \cdot 100 * * *$ & $166.004^{*}$ \\
\hline D.F. & & & 3 & 3 & 4 & 4 & 18 & 19 \\
\hline
\end{tabular}

a The ousiotype-specific mean is given by $\alpha_{\mathrm{og}}+\beta_{\mathrm{og}}^{\mathrm{L}} *($ trig $)+\beta_{\mathrm{og}}^{\mathrm{Q}} *(\text { trig })^{2}$, where $\alpha_{\mathrm{og}}, \beta_{\mathrm{og}}^{\mathrm{L}}$ and $\beta_{\mathrm{og}}^{\mathrm{Q}}$ are the intercept, slope and second order covariate parameters; o refers to ousiotype CC, CR or RR; and g refers to gender (F for females and $\mathrm{M}$ for males, respectively).

${ }^{\mathrm{b}}$ In these models the slopes were restricted to be equal among gender-dependent ousiotypes (e.g. $\beta_{\mathrm{CCF}}^{\mathrm{L}}=\beta_{\mathrm{CRF}}^{\mathrm{L}}=$ $\beta_{\mathrm{RRF}}^{\mathrm{L}} \neq 0$ and $\left.\beta_{\mathrm{CCM}}^{\mathrm{L}}=\beta_{\mathrm{CRM}}^{\mathrm{L}}=\beta_{\mathrm{RRM}}^{\mathrm{L}} \neq 0\right)$.

c In these models both the intercepts were restricted to be equal and the slopes were restricted to be equal among gender-dependent ousiotypes (e.g. $\alpha_{\mathrm{CCF}}=\alpha_{\mathrm{CRF}}=\alpha_{\mathrm{RRF}} \neq 0$ and $\alpha_{\mathrm{CCM}}=\alpha_{\mathrm{CRM}}=\alpha_{\mathrm{RRM}} \neq 0$; and $\beta_{\mathrm{CCF}}^{\mathrm{L}}=\beta_{\mathrm{CRF}}^{\mathrm{L}}=\beta_{\mathrm{RRF}}^{\mathrm{L}} \neq 0$ and $\left.\beta_{\mathrm{CCM}}^{\mathrm{L}}=\beta_{\mathrm{CRM}}^{\mathrm{L}}=\beta_{\mathrm{RRM}}^{\mathrm{L}} \neq 0\right)$.

Parentheses indicate that the value of the parameter was fixed to value defined by null hypothesis; — indicates that value was not included in the model.

$* p<0 \cdot 05, * * p<0 \cdot 01, * * * p<0 \cdot 001$.

pedigree for the non-transmitted environmental factor hypothesis and for the single gene hypothesis. The likelihood ratio criterion (Beaty 1980; Boehnke \& Moll 1989; Moll et al. 1989; Rebbeck et al. 1991) was used as a measure of the support. The likelihoods of the MG+ PG model and the ME + PG model were each computed for each pedigree using the MLEs (presented in Table 1) obtained for each model when all of the pedigree data were considered. These two likelihoods were used to calculate a pedigreespecific likelihood ratio, $\mathrm{LHR}=-2 \log _{\mathrm{e}}$ ((the likelihood under model MG $+\mathrm{PG}$ )/(the likelihood under model ME + PG)). A negative LHR for a particular pedigree indicates greater support for the model of a single non-transmitted environmental factor on a polygenic background than for a single gene with large effects. A positive LHR indicates greater support for the model of a single major gene on a polygenic background. The distribution of LHR was continuous (mean $=-0.08)$ with most pedigrees having values near zero, hence not supporting either hypothesis. The LHR distribution was also negatively skewed (skewness -5.00) suggesting more support for the presence of a non-transmitted 
Table 2. Maximum likelihood parameter estimates and $\chi^{2}$ statistics for a subsample of 661 individuals from 246 pedigrees supporting a single non-transmitted environmental factor etiology on polygenic background

\begin{tabular}{|c|c|c|c|}
\hline Parameter & $\mathrm{GT}_{14}$ & $\mathrm{ME}+\mathrm{PG} \pm$ s.E. & $\mathrm{MG}+\mathrm{PG}$ \\
\hline$p$ & $0 \cdot 865$ & $0 \cdot 847 \pm 0 \cdot 015$ & $0 \cdot 840$ \\
\hline$\alpha_{\mathrm{CCF}}$ & $192 \cdot 126$ & $195 \cdot 679 \pm 9 \cdot 053$ & $198 \cdot 820$ \\
\hline$\alpha_{\mathrm{CRF}}$ & $297 \cdot 758$ & $299 \cdot 696 \pm 11 \cdot 362$ & $288 \cdot 790$ \\
\hline$\alpha_{\mathrm{RRF}}$ & $544 \cdot 612$ & $545 \cdot 575 \pm 29 \cdot 522$ & $567 \cdot 935$ \\
\hline$\beta^{\mathrm{L}}{ }_{\mathrm{CCF}}$ & $0 \cdot 395$ & $0 \cdot 374 \pm 0 \cdot 630$ & $0 \cdot 364$ \\
\hline$\beta_{\mathrm{CRF}}^{\mathrm{L}}$ & $0 \cdot 395$ & $0 \cdot 374 \pm 0 \cdot 630$ & $0 \cdot 364$ \\
\hline$\beta_{\mathrm{RRF}}^{\mathrm{L}}$ & $0 \cdot 395$ & $0 \cdot 374 \pm 0 \cdot 630$ & $0 \cdot 364$ \\
\hline$\alpha_{\mathrm{CCM}}$ & $212 \cdot 141$ & $213 \cdot 628 \pm 8 \cdot 098$ & $213 \cdot 130$ \\
\hline$\alpha_{\mathrm{CRM}}$ & $367 \cdot 732$ & $369 \cdot 151 \pm 11 \cdot 319$ & $367 \cdot 914$ \\
\hline$\alpha_{\mathrm{RRM}}$ & $536 \cdot 352$ & $543 \cdot 892 \pm 18 \cdot 900$ & $556 \cdot 347$ \\
\hline$\beta^{\mathrm{L}}{ }_{\mathrm{CCM}}$ & $0 \cdot 335$ & $0 \cdot 331 \pm 0 \cdot 049$ & $0 \cdot 345$ \\
\hline$\beta^{\mathrm{L}}{ }_{\mathrm{CRM}}$ & $0 \cdot 335$ & $0 \cdot 331 \pm 0 \cdot 049$ & $0 \cdot 345$ \\
\hline$\beta_{\mathrm{RRM}}^{\mathrm{L}}$ & $0 \cdot 335$ & $0 \cdot 331 \pm 0 \cdot 049$ & $0 \cdot 345$ \\
\hline$\sigma_{p g}^{2}$ & $2819 \cdot 384^{\mathrm{a}}$ & $2865 \cdot 334^{\mathrm{a}}$ & $2660 \cdot 020$ \\
\hline$\sigma_{\mathrm{e}}^{2}$ & $309 \cdot 788$ & $314 \cdot 864 \pm 218 \cdot 564$ & $1118 \cdot 418$ \\
\hline$\tau_{1}$ & $0 \cdot 87$ & $(p)$ & $(1 \cdot 0)$ \\
\hline$\tau_{2}$ & $0 \cdot 641$ & (p) & $(0 \cdot 5)$ \\
\hline$\tau_{3}$ & $1 \cdot 0^{\mathrm{b}}$ & (p) & $(0 \cdot 0)$ \\
\hline$-\log _{e} \mathrm{~L}$ & $3876 \cdot 443$ & $3879 \cdot 414$ & $3894 \cdot 136$ \\
\hline$x^{2}$ & & $5 \cdot 941(\mathrm{NS})$ & $35 \cdot 387 *$ \\
\hline D.F. & & 2 & 1 \\
\hline
\end{tabular}

The ousiotype-specific mean is given by $\alpha_{\mathrm{og}}+\beta_{\mathrm{og}}^{\mathrm{L}} *\left(\right.$ trig), where $\alpha_{\mathrm{og}}$ and $\beta_{\mathrm{og}}^{\mathrm{L}}$ are the intercept and the slope; o refers to ousiotype CC, $\mathrm{CR}$ or RR; and $\mathrm{g}$ refers to gender ( $\mathrm{F}$ for females, $\mathrm{M}$ for males, respectively). The slopes were restricted to be equal among gender-dependent ousiotypes (e.g. $\beta_{\mathrm{CCF}}^{\mathrm{L}}=\beta_{\mathrm{CRF}}^{\mathrm{L}}=\beta_{\mathrm{RRF}}^{\mathrm{L}} \neq 0$ and $\beta_{\mathrm{CCM}}^{\mathrm{L}}=\beta_{\mathrm{CRM}}^{\mathrm{L}}=\beta_{\mathrm{RRM}}^{\mathrm{L}} \neq 0$ ). Parentheses indicate that the value of the parameter was fixed to value defined by null hypothesis.

a Because maximum likelihood estimates of $\sigma_{\mathrm{pg}}^{2}$ was at the boundary $\left(\sigma_{\mathrm{pg}}^{2}=\right.$ common variance $\left.\sigma_{\mathrm{ue}}^{2}\right)$ both in $\mathrm{GT}_{14}$ and $\mathrm{ME}+\mathrm{PG}$ models the proportion of the $\sigma_{\mathrm{pg}}^{2}$ attributable to additive effect of polygenes was fixed to the $0 \cdot 901$.

${ }^{\mathrm{b}}$ The $\tau_{3}$ of the $\mathrm{GT}_{14}$ was fixed at $\tau_{3}=1.0$ because the likelihood was maximized at this boundary in all instances. $* p<0.001$.

environmental factor in contrast to a single major gene.

We next removed pedigrees from the analysis with the largest positive LHR (hypothesized 'genetic' pedigrees) and tested the hypothesis of a non-transmitted environmental factor. After removal of eight pedigrees (representing 24 females and 26 males) with the largest positive LHR value, the ME + PG model fit the data for this subsample of 246 pedigrees as well as the $\mathrm{GT}_{14}$ model $\left(\chi^{2}=5.941\right.$, D.F. $\left.=2, p>0.05\right)$. The $\mathrm{MG}+\mathrm{PG}$ hypothesis was rejected for this subsample $\left(\chi^{2}=35.387\right.$, D.F. $\left.=1, p<0.001\right)$. The MLEs of the parameters obtained for these models are given in Table 2. The MLE of the polygenic variance $\left(\sigma_{\text {pg }}^{2}\right)$ was at the boundary $\left(\sigma_{\mathrm{pg}}^{2}=\sigma_{\text {ue }}^{2}\right)$ both in $\mathrm{GT}_{14}$ and $\mathrm{ME}+\mathrm{PG}$ models. Hence, we fixed the proportion of $\sigma^{2}$ ue attributable to the variance of the additive effects of polygenes $\left(\sigma_{\mathrm{pg}}^{2}\right)$ to 0.901 , which was the highest value obtained when the entire data set was considered (i.e. model ME $+\mathrm{PG}$ in Table 1). Similarly, the transmission parameter, $\tau_{3}$, of the $\mathrm{GT}_{14}$ model, was fixed at 1.0 because the likelihood was maximized at this boundary in all instances.

We then removed pedigrees with the largest negative LHR (hypothesized 'environmental' pedigrees) and tested the hypothesis of a single major gene. After removing as many as 116 pedigrees with the largest negative LHR value, we still rejected the $\mathrm{MG}+\mathrm{PG}$ model for the remaining subsample. We conclude from these results that the majority of pedigrees in the entire sample of pedigrees considered in this study supported the hypothesis that a nontransmitted environmental factor on a polygenic background explains the significant differences among the intercepts associated with ousiotypes.

In order to compare the distribution of $\mathrm{Na}-\mathrm{Li}$ 
Table 3. Average gender-specific Na-Li CNT and plasma triglyceride levels and respective standard deviations within ousiotype classes

\begin{tabular}{|c|c|c|c|c|c|}
\hline \multirow[b]{2}{*}{ Ousiotype } & \multirow[b]{2}{*}{$\mathrm{N}$} & \multicolumn{2}{|c|}{ Na-Li CNT } & \multicolumn{2}{|c|}{ Triglyceride } \\
\hline & & Mean & S.D. & Mean & S.D. \\
\hline \multicolumn{6}{|l|}{ Females } \\
\hline $\mathrm{CC}$ & 223 & $222 \cdot 975$ & $53 \cdot 188$ & $112 \cdot 677$ & $58 \cdot 793$ \\
\hline CR & 49 & $384 \cdot 115$ & $47 \cdot 314$ & $123 \cdot 102$ & $62 \cdot 857$ \\
\hline $\mathrm{RR}$ & 5 & $563 \cdot 812$ & $65 \cdot 756$ & $70 \cdot 600$ & 18.955 \\
\hline$F_{2,274}$ & & $276 \cdot 71^{*}$ & $0 \cdot 726(\mathrm{NS})$ & $1.98(\mathrm{NS})$ & $2 \cdot 83(0 \cdot 06)$ \\
\hline \multicolumn{6}{|l|}{ Males } \\
\hline $\mathrm{CC}$ & 218 & $257 \cdot 326$ & $61 \cdot 079$ & $137 \cdot 280$ & $79 \cdot 031$ \\
\hline CR & 63 & $445 \cdot 698$ & 73.952 & $144 \cdot 270$ & $79 \cdot 465$ \\
\hline $\mathrm{RR}$ & 5 & $598 \cdot 392$ & $38 \cdot 464$ & $85 \cdot 600$ & $27 \cdot 437$ \\
\hline$F_{2,283}$ & & $266 \cdot 33^{*}$ & & $1 \cdot 32(\mathrm{NS})$ & \\
\hline $\mathrm{B}_{2}$ & & & $2 \cdot 53(0 \cdot 08)$ & & $2 \cdot 37(0 \cdot 09)$ \\
\hline
\end{tabular}

Probable ousiotype assignments (CC, CR or RR) were made for each individual whose ousiotype probability was equal to or greater than 0.7. CC, CR and RR refer to respective gender-specific ousiotype classes. Analysis of variance was used to test heterogeneity of mean levels and Bartlett's test to test heterogeneity of variances among ousiotype classes.

${ }^{*} p<0 \cdot 001$, other probability levels of these tests are given in parentheses.

CNT and plasma triglyceride levels among individuals assigned to the different ousiotype classes under the ME $+\mathrm{PG}$ model for the subsample of 246 pedigrees, we next calculated ousiotype probabilities for each individual. Probable ousiotype assignments (CC, CR or RR) were made for each individual whose ousiotype probability was equal to or greater than $0 \cdot 7$. We were able to classify 277 females and 286 males; $98(14.8 \%)$ individuals remained unclassifiable. Of the classifiable females, ousiotype assignments were $223 \mathrm{CC}, 49 \mathrm{CR}$ and $5 \mathrm{RR}$. In males the respective numbers were $218 \mathrm{CC}, 63 \mathrm{CR}$ and 5 RR. There were significant differences in the mean Na-Li CNT level, but not the average level of plasma triglycerides, among ousiotypes (Table 3). The intraousiotype variance of Na-Li CNT was not significantly heterogeneous among ousiotypes for females (Bartlett's test, $p=0 \cdot 726$ ) but was heterogeneous for males at the 0.08 level of probability. Intraousiotype variances of plasma triglyceride levels were heterogeneous for females $(p=0 \cdot 06)$ and for males $(p=0 \cdot 09)$. These findings suggest that variation in an unknown non-transmitted environmental factor is responsible for the differences in Na-Li CNT means among the ousiotypes and for heterogeneity of intraousiotype variances of Na-Li CNT and plasma triglyceride levels in this selected data set.

We next tested the null hypothesis of homogeneity of the profile of the means of coronary heart disease (CHD) risk factor trait phenotypes among ousiotype classes. We employed multivariate analysis of variance (MANOVA) recognizing that individuals falling in the distinct ousiotype categories are not statistically independent. Hence, the computed type I errors are only approximations. Each profile included standardized means for age, height (HGT), weight (WGT), body mass index (BMI), waist to hip ratio (WST/HIP), systolic (SBP) and diastolic (DBP) blood pressure, and apolipoproteins B (apoB), AI (apoAI), AII (apoAII), CII (apoCII), CIII (apoCIII), E (apoE) and total and HDL cholesterol (Fig. 1). The ousiotype profiles were not parallel for females (Wilks' Lambda $=0 \cdot 874, F=1 \cdot 609, \quad$ D.F. $=(28,522)$, $p<0.05$ ) or males (Wilks' Lambda $=0.867, F=$ $1 \cdot 422$, D.F. $=(28,540), p=0 \cdot 07)$. Considering each trait separately, statistically significant differences among ousiotype classes were observed for WGT, BMI and HDL-C in females and for age in males when a 0.05 test criterion was considered. In addition, differences among ousiotypes for apoAII and apoCII were 

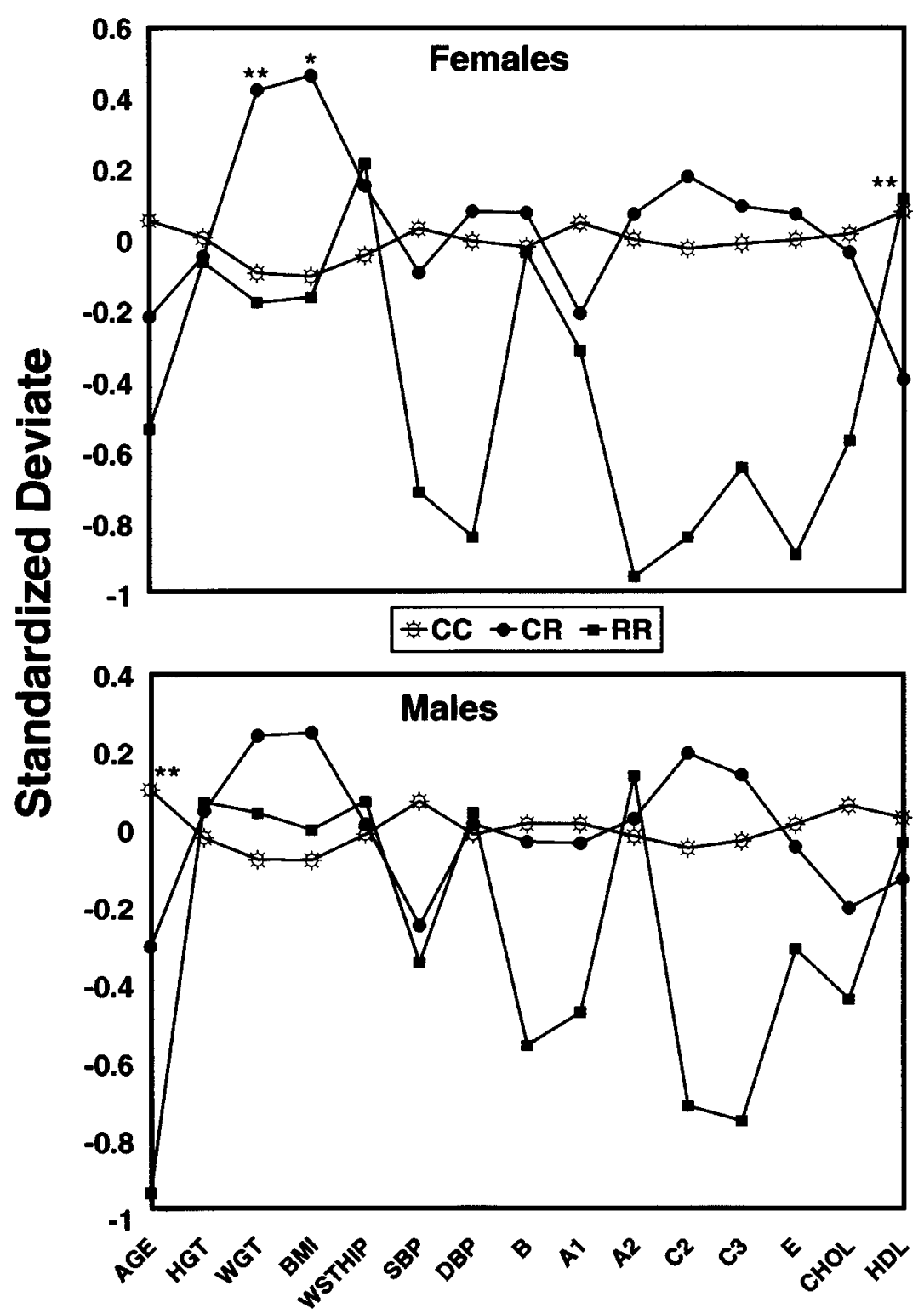

Fig. 1. Gender-specific ousiotype phenotype profiles. The profile included age, height (HGT), weight (WGT), body mass index (BMI), waist to hip ratio (WST/HIP), total and HDL cholesterol and systolic (SBP) and diastolic (DBP) blood pressure. Each variable was transformed to a standardized deviate $(\mathrm{N}(0,1))$ for all three ousiotypes combined. The points represent the trait means of each ousiotype class. The ousiotype profiles were not parallel for females (Wilks' Lambda $=0 \cdot 874, F=1 \cdot 609$, D.F. $=(28,522), p<0 \cdot 05$ ) or for males $($ Wilks' Lambda $=0 \cdot 867, F=1 \cdot 422$, D.F. $=(28,540), p=0 \cdot 07)$.

significant among females at the $0 \cdot 10$ level of statistical significance $(p<0.09$ and $p<0.075$, respectively) and for WGT, BMI, SBP and apoCII among males $(p<0.082, p<0.071, p<$ 0.061 and $p<0.066$, respectively). These findings suggest that variation in the proposed unknown non-transmitted environmental factor, which has large effects on Na-Li CNT, results in three classes of individuals with heterogeneity in measures of body size, lipid metabolism and blood pressure.

We then compared the phenotype profiles of the classifiable individuals (A) with unclassifiable individuals (B) and those who were a priori excluded from the sample (C) (Fig. 2). The profiles were not parallel across groups for females (Wilks' Lambda $=0 \cdot 838, F=4 \cdot 350$, D.F. $=(28,1322), p<0.0001)$ or for males (Wilks' 


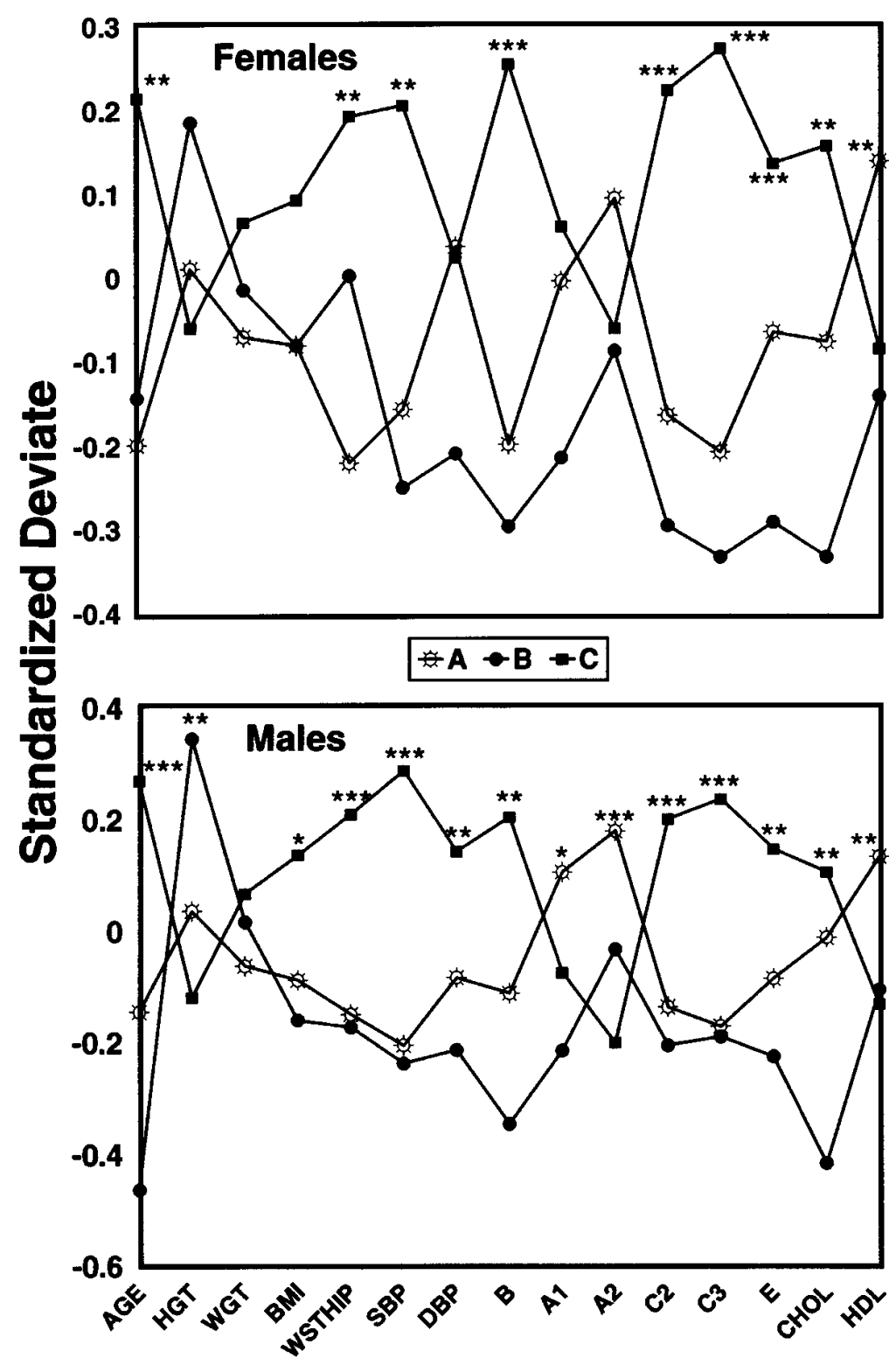

Fig. 2. Gender-specific phenotype profiles of the classifiable individuals (A) with unclassifiable individuals (B) and those who were a priori excluded from the sample (C). The profile battery included age, height (HGT), weight (WGT), body mass index (BMI), waist to hip ratio (WST/HIP), total and HDL cholesterol and systolic (SBP) and diastolic (DBP) blood pressure. Each variable was transformed to a standardized deviate $(\mathrm{N}(0,1))$ for all three groups combined. The points represent the trait means of each group. The profiles were not parallel across groups for females (Wilks' Lambda $=0 \cdot 838, F=4 \cdot 350$, D.F. $=(28,1322)$, $p<0 \cdot 0001$ ) or for males (Wilks' Lambda $=0 \cdot 835, F=3 \cdot 863$, D.F. $=(28,1150), p<0 \cdot 0001$ ).

Lambda $=0 \cdot 835, F=3 \cdot 863$, D.F. $=(28,1150)$, $p<0 \cdot 0001)$. When each trait was considered separately, a statistically significant difference (with a 0.05 test criterion) among $\mathrm{A}, \mathrm{B}$ and $\mathrm{C}$ groups was obtained for all traits except HGT $(p=0 \cdot 128)$, WGT $(p=0 \cdot 251)$, BMI $(p=0 \cdot 079)$ and $\operatorname{DBP}(p=0 \cdot 116)$ in females and WGT $(p=$ 0.323 ) in males. The profiles of a priori excluded individuals indicated they were on average older, had higher average BMI and waist to hip ratios, apoB, apoCII, apoCIII, and apoE, total plasma cholesterol levels and systolic blood pressure, and lower average apoAII and HDL cholesterol levels than individuals used in the complex segregation analysis.

We then compared Na-Li CNT and plasma triglyceride levels among the A, B and $\mathrm{C}$ groups. Hypotheses of homogeneity of means and 
Table 4. Average gender-specific Na-Li CNT and plasma triglyceride levels and respective standard deviations among three groups of individuals, those who were classifiable at $\mathrm{p}>0 . \%(A)$, those who were unclassifiable $(B)$ and those who were a priori excluded from the sample $(C)$

\begin{tabular}{|c|c|c|c|c|c|}
\hline \multirow[b]{2}{*}{ Group } & \multirow[b]{2}{*}{$N$} & \multicolumn{2}{|c|}{ Na-Li CNT } & \multicolumn{2}{|c|}{ Triglyceride } \\
\hline & & Mean & S.D. & Mean & S.D. \\
\hline \multicolumn{6}{|l|}{ Females } \\
\hline A & 277 & $257 \cdot 632$ & $90 \cdot 755$ & $113 \cdot 762$ & $59 \cdot 354$ \\
\hline B & 86 & $305 \cdot 084$ & $86 \cdot 658$ & $106 \cdot 942$ & $54 \cdot 523$ \\
\hline $\mathrm{C}$ & 310 & $305 \cdot 690$ & $119 \cdot 301$ & $146 \cdot 365$ & $85 \cdot 686$ \\
\hline$F_{2,670}$ & & $17 \cdot 16^{*}$ & & $19 \cdot 07 *$ & \\
\hline $\mathrm{B}_{2}$ & & $13 \cdot 54^{*}$ & & $25 \cdot 07^{*}$ & \\
\hline \multicolumn{6}{|l|}{ Males } \\
\hline $\mathrm{A}$ & 286 & $304 \cdot 783$ & $108 \cdot 053$ & $137 \cdot 916$ & $78 \cdot 722$ \\
\hline B & 56 & $358 \cdot 921$ & $88 \cdot 456$ & $127 \cdot 911$ & $55 \cdot 529$ \\
\hline $\mathrm{C}$ & 245 & $345 \cdot 397$ & $131 \cdot 559$ & $163 \cdot 636$ & $80 \cdot 098$ \\
\hline$F_{2,584}$ & & $9 \cdot 67 *$ & & $9 \cdot 30^{*}$ & \\
\hline $\mathrm{B}_{2}$ & & $8 \cdot 91 *$ & & $5 \cdot 43 *$ & \\
\hline
\end{tabular}

Analysis of variance was used to test heterogeneity of mean levels and Bartlett's test to test heterogeneity of variances among these groups.

$* p<0 \cdot 01$.

variances among the groups were rejected for both Na-Li CNT and plasma triglyceride levels (Table 4). Individuals excluded a priori had higher average Na-Li CNT and plasma triglyceride levels.

\section{DISCUSSION}

We began this study by testing the hypothesis that a single unmeasured gene that is associated with large effects on Na-Li CNT level also has effect on the covariation between Na-Li CNT and plasma triglyceride levels through pleiotropy. The role of lipids in the regulation of cell membrane function (Kaplan, 1990) is the biological basis for this hypothesis. The cell membrane is composed of proteins and lipids and is the framework for a number of transport systems, including Na-Li CNT, that control ionic fluxes across cell membranes (Postnov \& Orlov 1985). The physicochemical functions of cell membranes can be modified by the interaction of cell membrane lipids with plasma lipids (Rutherford et al. 1992a). For example, increased human platelet, erythrocyte, and lymphocyte cell membrane fluidity, which influences ion efflux across cell membranes, is associated with elevations in plasma triglyceride levels (Muller 1990; Carr et al. 1993). The observed positive linear relationship between $\mathrm{Na}-\mathrm{Li}$ CNT and plasma triglyceride levels is consistent with the proposed biological influence of plasma lipids on membrane fluidity and enhanced lithium efflux across the erythrocyte cell membranes. However, homogeneity of the gender-specific slopes among ousiotypes argues against pleiotropic effects of a single unmeasured gene or the influence of variation in a single unmeasured environmental factor on the covariation between Na-Li CNT and plasma triglyceride levels in our selected sample from the Rochester, MN, population.

The majority of pedigrees supported the presence of variation in a single unmeasured nontransmitted environmental factor with large effects on the Na-Li CNT distribution when the effects of polygenes and of the gender-specific linear relationship with plasma triglyceride levels was taken into account in the complex segregation models. There were also a few pedigrees which probably supported the single gene hypothesis, because these pedigrees had to be excluded from the data set to obtain statistically significant support for the environmental factor hypothesis among the remaining pedigrees. We were not, however, able to confirm the single gene hypothesis although we employed complex segregation models for a subsample that included only these hypothesized 'genetic' pedigrees and 
16 adjacent pedigrees from the 'genetic' tail of the LHR distribution $\left(\chi^{2}=10 \cdot 970\right.$, D.F. $=1$, $p<0.001)$.

Our findings are consistent with a recent genetic study that suggested, in part, an environmental explanation of the multimodality of the Na-Li CNT distribution in a sample of adult individuals from the same Rochester, MN, population (Rebbeck et al. 1991). In the earlier study, Rebbeck et al. found four gender-specific ousiotype-classes, two in females and two in males (Rebbeck et al. 1991). In our study a $\mathrm{ME}+\mathrm{PG}$ model with four gender-and ousiotypespecific intercepts and common gender-specific slope was rejected with $\chi^{2}=98 \cdot 132$ (D.F. $=12$, $p<0.001$ ) in favour of six gender- and ousiotypespecific intercepts and a common gender-specific slope. Rebbeck et al. also found evidence for the presence of the segregation of effects of a single genetic factor in some families (Rebbeck et al. 1991). However, five of the eight hypothesized 'genetic' pedigrees that we removed from the 'final' complex segregation analyses were not among the pedigrees that Rebbeck et al. found to support the hypothesis of a single gene with major effects on the Na-Li CNT distribution. One reason for differences between the study of Rebbeck et al. (Rebbeck et al. 1991) and our study might simply be explained by our sample considering mainly healthy subjects in contrast to the sample considered in the study of Rebbeck et al. A second reason may be that different variables were modelled; we did not adjust the Na-Li CNT data for variation in other concomitants prior to complex segregation analyses as did Rebbeck et al. (Rebbeck et al. 1991). Applications of complex segregation analyses to data adjusted for concomitants may influence the inferences about the nature of the major factor (Pérusse et al. 1991; Rebbeck et al. 1991; Borecki et al. 1993).

Stratification by the proposed unknown nontransmitted environmental factor resulted in three classes of individuals with significant heterogeneity in the distributions of coronary heart disease risk factor traits, as well as interindividual variation in both Na-Li CNT and plasma triglyceride levels. The finding that average weight and BMI were heterogeneous among these strata both in females and in males when each of the CHD risk factor traits was considered separately suggests that body size itself and/or factor(s) associated with weight regulation, such as insulin resistance, hyperinsulinemia, lack of physical activity and/or a particular dietary habit is (are) potential candidate(s) for the unknown environmental factor detected by our study. This is consistent with previous studies suggesting that variation in body size is associated with variation in blood pressure, in plasma content and composition of lipids and lipoproteins, including plasma triglyceride levels (Ferrannini et al. 1991), and in Na-Li CNT (Bunker et al. 1993). This is also consistent with a recent report that insulin may modulate kinetics of Na-Li CNT (Pontremoli et al. 1994).

Phenotypic characteristics of a priori excluded individuals resembled trait values that are expected to be associated with individuals at greater risk to CHD. They were on average older, had higher average waist to hip ratios, total plasma cholesterol levels and systolic blood pressure, and lower average HDL cholesterol levels than individuals used in the complex segregation analysis. Furthermore, they had higher average Na-Li CNT and plasma triglyceride levels. This finding may further serve to explain the absence of evidence for the major gene hypothesis in this study as the allelic variations with large phenotypic effects may be rare and found mainly in myocardial-infarctionprone pedigrees (Hasstedt et al. 1988).

The traits that are risk factors for CHD combine to form a coherent network within which covariance between traits is constrained in order to maintain homeostatic responses to external perturbations (Ferrannini 1991; Sing \& Reilly 1993). Traits which are functionally related, such as those regulating blood pressure and lipid metabolism, are usually organized into subsystems within which strong physiologic forces are working between the traits (Sing \& Reilly 1993). Weaker physiologic forces are 
working between the traits of different subsystems. Because Na-Li CNT is associated with blood pressure regulation, and plasma triglyceride level is an integral part of lipid metabolism (i.e. these two traits represent distinct subsystems), we might expect a weak relationship between $\mathrm{Na}-\mathrm{Li} \mathrm{CNT}$ and plasma triglyceride levels that would vary among strata of the population. However, observed homogeneity of the gender specific slopes among the ousiotypes argues for strong invariant, gender specific, effects of the causation(s) of the association between Na-Li CNT and plasma triglyceride levels.

In conclusion, our study confirms the complex contribution of variation in genetic and environmental factors to Na-Li CNT variability in a selected sample of 'healthy' people from the RFHS. This complex multifactorial etiology of interindividual variation in the $\mathrm{Na}-\mathrm{Li} \mathrm{CNT}$ phenotype impedes our ability to establish genetic and/or environmental sources for interindividual variation of $\mathrm{Na}-\mathrm{Li} \mathrm{CNT}$ or to relate variation in these factors to variation in blood pressure and risk of hypertension in population at large. This is because the phenotype of a complex quantitative trait such as Na-Li CNT does not segregate as a simple Mendelian trait in the majority of families, and the mapping between variation in the genotype (and/or environment) and variation in the phenotype is not one-to-one (Sing et al. 1988, 1994, 1996; Sing \& Reilly 1993). One possibility to add to our understanding of the complex expression of Na-Li CNT phenotype is the utilization of more precise kinetic measures of Na-Li CNT as suggested by Rutherford (Rutherford et al. $1992 a, b)$. An alternative approach which deals with complexity of the relationship between variation in causation and variation in a trait in the population at large that deserves more consideration is one that asks how many models (combinations of genetic and environmental agents), rather than which model, explain the observed distribution of Na-Li CNT (Congdon et al. 1993).

This study was supported by NIH grants HL 30428 and HL 39107. J.H.S. was partly supported by a
Visiting Research Fellowship from the Academy of Finland, Medical Research Council. We appreciate the helpful comments on the manuscript that were made by Drs Pat Peyser, Sharon Reilly Kardia and Martha Haviland.

\section{REFERENCES}

Annest, J. L., Sing, C. F., Biron, P. \& Mongeau, J. G. (1979). Familial aggregation of blood pressure and weight in adoptive families. II. Estimation of the relative contributions of genetic and common environmental factors to blood pressure correlations between family members. Am. J. Epidemiol. 110 , $492-503$.

Beaty, T. H. (1980). Discriminating among single locus models using small pedigrees. Am. J. Med. Genet. 6, 229-240.

Boennke, M. \& Moll, P. P. (1989). Identifying pedigrees segregating at a major locus for a quantitative trait: an efficient strategy for linkage analyses. Am. J. Hum. Genet. 44, 216-224.

Boerwinkle, E., Turner, S. T., Weinshilboum, R., Johnson, M., Richelson, E. \& Sing, C. F. (1986). Analysis of the distribution of erythrocyte sodium lithium countertransport in a sample representative of the general population. Genet. Epid. 3, 365-378.

Boerwinkle, E., Visvikis, S., Welsh, D., Steinmetz, J., Hanash, S. M. \& Sing, C. F. (1987). The use of measured genotype information in the analysis of quantitative phenotypes in man. II. The role of the apolipoprotein E polymorphism in determining levels, variability, and covariability of cholesterol, betalipoprotein, and triglycerides in a sample of unrelated individuals. Am. J. Med. Genet. 27, 567-582.

Borecki, I. B., Bonney, G. E., Rice, T., Bouchard, C. \& RAO, D. C. (1993). Influence of genotype-dependent effects of covariates on the outcome of segregation analysis of the body mass index. Am. J. Hum. Genet. 53, 676-687.

Bunker, C. H., Wing, R. R., Becker, D. J. \& Kuller, L. H. (1993). Sodium-lithium counter-transport activity is decreased after weight loss in healthy obese men. Metabolism 42(8), 1052-1058.

Canessa, M., Adragna, N., Solomon, H. S., Connolly, T. M. \& Tosteson, D. C. (1980). Increased sodiumlithium countertransport in red cells of patients with essential hypertension. N. Engl. J. Med. 302, 772-776.

Canessa, M. L. \& Tosteson, D. C. (1979). Determination of the sodium-lithium countertransport system of human erythrocytes. In Lithium controversies and unresolved issues (eds. T. B. Cooper, G. Gershown, N. S. Kline \& M. Schou), pp. 978-982. Amsterdam: Excerpta Medica.

Cannings, C., Thompson, E. A. \& Skolnick, M. H. (1978). Probability functions on complex pedigrees. Am. J. Hum. Genet. 10, 26-61.

Carr, P., Taub, N. A., Watts, G. F. \& Poston, L. (1993). Human lymphocyte sodium-hydrogen exchange. The influences of lipids, membrane fluidity, and insulin. Hypertension 21, 344-352.

Congdon, C. B., Sing, C. F. \& Reilly, S. L. (1993). Genetic algorithms for identifying combinations of genes and other risk-factors associated with coronary artery disease. 13th international joint conference on artificial intelligence, pp. 107-117. Workshop on Artificial Intelligence and Genome.

Dadone, M. M., Hasstedt, S. J., Hunt, S. C., Smith, J. 
B., Ash, K. O. \& Williams, R. R. (1984). Genetic analysis of sodium-lithium countertransport in 10 hypertension-prone kindreds. Am. J. Med. Genet. 17, $565-577$.

Elston, R. C. \& Stewart, J. (1971). A general model for the genetic analyses of pedigree data. Hum. Hered. 21, $523-542$.

Ferrannini, E. (1991). Metabolic abnormalities of hypertension. A lesson in complexity. Hypertension 18(5), 636-639.

Ferrannini, E., Haffner, S. M., Mitchell, B. D. \& Stern, M. P. (1991). Hyperinsulinaemia: the key feature of a cardiovascular and metabolic syndrome. Diabetologia 34, 416-422.

Hasstedt, S. J. \& Cartwright, P. (1981). PAP: Pedigree Analysis Program. Tech. Rep. 13. Salt Lake City, UT: Department of Medical Biophysics and Computing, University of Utah.

Hasstedt, S., Wu, L. L., Ash, K. O., Kuida, H. \& Williams, R. R. (1988). Hypertension and sodiumlithium countertransport in Utah pedigrees: evidence for major-locus inheritance. Am. J. Hum. Genet. 43, $14-22$.

Hixson, J. E. \& Powers, P. K. (1994). Detection and characterization of new mutations in the human angiotensinogen gene (AGT). Hum. Genet. 96, 110-112.

Hunt, S. C., Williams, R. R., Smith, J. B. \& Ash, K. O. (1986). Associations of three erythrocyte cation transport systems with plasma lipids in Utah subjects. Hypertension 8(1), 30-36.

Jeunemaitre, X., Soubrier, F., Kotelevtsev, Y. V., Lifton, R. P., Williams, C. S., Charru, A., Hunt, S. C., Hopkins P. N., Williams, R. R., Lalouel, J-M. \& Corvol, P. (1992). Molecular basis of human hypertension: role of angiotensinogen. Cell 71, 169-180.

Kaplan, N. M. (1990). Primary hypertension: pathogenesis. Clinical hypertension, 5th edn, pp. 54-111. Baltimore, MD : Williams \& Wilkins.

Kottke, B. A., Mold, P. P., Michels, V. V. \& Weidman, W. H. (1991). Levels of lipids, Lipoproteins, and apolipoproteins in a defined population. Mayo. Clin. Proc. 66, 1198-1208.

Lalouel, J. M. (1979). Gemini : A Computer Program for Optimization of a Nonlinear Function. Tech. Rep. 14. Salt Lake City, UT : Department of Medical Biophysics and Computing, University of Utah.

Lalouel, J. M., Rao, D. C., Morton, N. E. \& Elston, R. C. (1983). A unified model for complex segregation analysis. Am. J. Hum. Genet. 35, 816-826.

Miall, W. E. \& Oldham, P. D. (1963). The hereditary factor in arterial blood pressure. Br. Med. J. i, 75-80.

Moll, P. P., Michels, V. V., Weidman, W. H. \& Kоттке, B. A. (1989). Genetic determination of plasma apolipoprotein AI in a population-based sample. Am. J. Hum. Genet. 44, 124-139.

MULLER, S. (1990). Rheological properties and membrane fluidity of red blood cells and platelets in primary hyperlipoproteinemia. Atherosclerosis 83, 231-237.

Pérusse, L., Mold, P. P. \& Sing, C. F. (1991). Evidence that a single gene with gender- and age-dependent effects influences systolic blood pressure determination in a population-based sample. Am. J. Hum. Genet. 49: 94-105.

Pickering, G. W. (1967). The inheritance of arterial pressure. In The epidemiology of hypertension (eds. J. Stamler, R. Stamler \& T. N. Pullman), pp. 18-27. New York: Grune and Stratton.
Pontremoli, R., Zerbini, G., Rivera, A. \& Canessa, M. (1994). Insulin activation of red blood cell $\mathrm{Na}^{+} / \mathrm{H}^{+}$ exchange decreases the affinity of sodium sites. Kidney Intl. 46, 365-375.

Postnov, Y. V. \& ORLov, S. N. (1985). Ion transport across plasma membrane in primary hypertension. Physiol. Rev. 65(4), 904-945.

Rebbeck, T. R., Turner, S. T., Michels, V. V.\& Moll, P. P. (1991). Genetic and environmental explanations for the distribution of sodium-lithium countertransport in pedigrees from Rochester, MN. $A m$. J. Hum Genet. 48, 1092-1104.

Reilly, S. L., Ferrell, R. E., Kottke, B. A., Камвон, M. I. \& SING, C. F. (1991). The gender-specific apolipoprotein $\mathrm{E}$ genotype influence on the distribution of lipids and apolipoproteins in the population of Rochester, MN. I. Pleiotropic effects on means and variances. Am. J. Hum. Genet. 49, 1155-1166.

Reilly, S. L., Ferrell, R. E., Kottke, B. A. \& Sing, C. F. (1992). The gender-specific apolipoprotein E genotype influence on the distribution of plasma lipids and apolipoproteins in the population of Rochester, Minnesota. II. Regression relationships with concomitants. Am. J. Hum. Genet. 51, 1311-1324.

Reilly, S. L., Ferrell, R. E. \& Sing, C. F. (1994). The gender-specific apolipoprotein $\mathrm{E}$ genotype influence on the distribution of plasma lipids and apolipoproteins in the population of Rochester, Minnesota. III. Correlations and covariances. Am. J. Hum. Genet. 55, 1001-1018.

Rutherford, P. A., Thomas, T. H. \& Wilkinson, R. (1992a) Erythrocyte sodium-lithium countertransport: clinically useful, pathophysiological instructive or just phenomenology? Clin. Sci. 82, $341-352$.

Rutherford, P. A., Thomas, T. H., Laker, M. F. \& Wilkinson R. (1992b) Plasma lipids affect maximum velocity not sodium affinity of human sodium-lithium countertransport: distinction from essential hypertension. Eur. J. Clin. Invest. 22, 719-724.

Sing, C. F. \& Boerwinkle, E. (1985). The genetics of blood pressure variability: An overview. In Children's blood pressure, report of the eighty-eighth Ross conference on pediatric research (eds. L. J. Filer Jr \& R. M. Lauer), pp. 35-43. Columbus, $\mathrm{OH}$ : Ross Laboratories.

Sing, C. F., Boerwinkle, E., Moll, P. P.\& Templeton, A. R. (1988). Characterization of genes affecting quantitative traits in humans. In Proceedings of the 2nd international conference on quantitative genetics (eds. B. Weir, E. J. Eisen, M. M. Goodman, \& R. Namkoong), pp. 250-269. Sunderland, MA: Sinauer.

Sing, C. F., Boerwinkle, E. \& Turner, S. T. (1986). Genetics of primary hypertension. Clin. Exper Hypertens A8(4\&5), 623-651.

Sing, C. F., Haviland, M. B. \& Reillly, S. L. (1996). Genetic architecture of common multi-factorial diseases. In Variation in the human genome, Ciba Foundation Symposium 197 (eds. D. J. Chadwick, G. Cardew), pp 211-232. Chichester: John Wiley \& Sons. Sing, C. F. \& Reilly, S. L. (1993). Genetics of common diseases that aggregate, but do not segregate, in families. In Genetics of cellular, individual, family, and population variability (eds. C. F. Sing \& C. L. Hanis), pp 140-161. New York: Oxford University Press. 
Sing, C. F., Zerba, K. E. \& Reilly, S. L. (1994). Traversing the biological complexity in the hierarchy between genome and CAD endpoints in the population at large. Clin. Genet. 46, 6-14.

Titterington, D. M., Smith, A. F. M. \& Makov, U. E. (1985). Statistical analysis of finite mixture distributions. New York: John Wiley \& Sons.

Turner, S. T. \& Michels, V. V. (1991). Sodium-lithium countertransport and hypertension in Rochester, MN. Hypertension 18, 183-190.
Turner, S. T., Weidman, W. H., Michels, V. V., Reed, T. J., Ormson, C. L., Fuller, T. \& Sing, C. F. (1989) Distribution of sodium-lithium countertransport and blood pressure in Caucasians five to eighty-nine years of age. Hypertension 13(4), 378-391.

WARD, R. (1990). Familial aggregation and genetic epidemiology of blood pressure. In Hypertension: pathophysiology, diagnosis, and management (eds. J. H. Laragh \& B. M. Brenner), pp. 81-100. New York: Raven Press Ltd. 